\title{
NON-LINEAR MODEL OF A SYNCHRONOUS GENERATOR FOR DYNAMIC SIMULATIONS, TRAINING AND TEACHING
}

\author{
Tsotie Wamba Juste Student, Ekemb Gabriel, student René Wamkeue, Senior Member IEEE \\ Département de sciences appliquées \\ Université du Québec en Abitibi-Témiscamingue \\ 445 , boul. de l'Université, Rouyn-Noranda, \\ Québec, Canada J9X 5E4, Tel: (819) 762-0971/2240 \\ Juste.Tsotie-Wamba@uqat.ca, rene.wamkeue@uqat.ca,_Gabriel.Ekemb@uqat.ca
}

\begin{abstract}
The development of digital and simulation tools is a major challenge for the teaching of electromechanics and related fields, as their suitability depends both on scientific and educational requirements. In this regard, this paper presents a synchronous generator model, developed for the teaching and training in the hydroelectric field. The model developed with MATLAB/SIMULINK and having the characteristics of being dynamic, versatile, flexible and easily integrated in most electrical power generation system using synchronous generator, is made of a mechanical part, an electrical part, and an excitation circuit. It is a dynamic nonlinear model which can perform most of the simulations of real life situations by acting on the load and presenting the resulting curves. Moreover, it allows direct simulation without the need for initial conditions re-evaluation. In this paper, its stepwise system development is covered alongside its subsystems. Our results indicate a successful application of the developed model in a complete hydropower system production, and suggest the importance of such tool.
\end{abstract}

Keywords: Synchronous generator model, flexible, versatile and non linear model, training and educational tool, Matlab/Simulink.

\section{INTRODUCTION}

Numerous references recognized the effort needed to motivate students in laboratory work, particularly in the fields of machines, drives and renewable energy [1-5]. More research has been carried out to include virtual laboratories that aim to enhance learning $[6,7]$ or as an alternative to real laboratories $[8,9]$. The development of virtual laboratories requires the implementation of appropriate digital elements models that fulfill both scientific and educational requirements. Among the elements widely used in electrical and electromechanical engineering teaching, the synchronous generator (SG) plays a pivotal role. In fact, synchronous generators are used almost exclusively in power systems as source of electrical energy. The generator is supply with mechanic power from a prime mover, usually a turbine, whilst the excitation is provided by an excitation system [10]. Several works on SG modeling have been reported in the literature. In many cases as in hydropower plants, rotor dynamics are used for its implementation [11-13]. However, the theoretical or practical teaching on the SG, should also demonstrate the key role of excitation system and its automatic voltage regulator (AVR) as well as the electrical part. In most cases, when the full model is used [14-16], electrical equations are simply incorporated into Simulink's blocks. Although these models are mostly dedicated to the prediction, they are in general unable to be used in identification, optimisation and diagnosis programs. A large number of state-based SG models that contributes to solve these problems are presented in the literature. However, some improvement is still required. In fact, either the choice of the control variables of the model depends on the desired simulations [17] or it doesn't facilitate a series of simulations replicating real life situations [18]. In both cases, it must be either incorporated the rotor dynamics, or improve it in order to obtain a model that is flexible and suitable for electrical energy generation systems using a SG. They are thus either not versatile or flexible. Nevertheless Matlab became a standard tool for flexible technical computing and Simulink became an interactive tool for modeling, simulating, and analyzing dynamic systems. Simulink offers a set of tools that can be used to build complicated systems from a library of built-in blocks and allows the creation of custom blocks that incorporate $\mathrm{C} / \mathrm{C}++$, FORTRAN, or Matlab codes [11]. This features make MATLAB/Simulink a better choice for nonlinear dynamics models.

In this paper, Matlab/Simulink program is used to propose a numerical model of a SG (Fig. 1), suitable for training and teaching. The proposed SG model in a nonlinear state form can be used to perform almost all simulations, for 
parameter identification, optimization and diagnosis processes. The strategy used to include the mechanical power makes the model adequate for most electrical power generation systems using $\mathrm{SG}$ and training or didactical tools [19]. Operations are performed as in a real life situation.

This paper is organized into four sections. The first part focuses on the overall model while highlighting the process of its integration into systems of electric power generation. The second part presents the process of modeling various subsystems. The third part focuses on the utilization and the final part presents some results with the model inserted in a complete system of hydropower production.

\section{PRESENTATION OF THE SYSTEM}

The full system of hydropower plant is depicted by Fig. 1. It consists of the hydraulic circuit, the control circuit and the generator. The generator and the excitation system which are the focus this paper are limited by the dotted area. It consists of both electrical and mechanical parts, the excitation system and the islanded load. For its operation, the rotational speed is provided by the mechanical part. It is maintained constant by the speed controller through a balance between the mechanical and the active electrical power via a comparator. The mechanical power is generated by water energy due to the elevation and the active power is consumed by the load. The load also consumes the reactive power that is compensated by the excitation circuit through the field current. This helps to keep the voltage at the generator output constant. The presented model is able to produce all the desired curves.

The features of Matlab/Simulink facilitate the use of exogenous variables to implement nonlinear state models of various sub-systems through $\mathrm{S}$-functions.

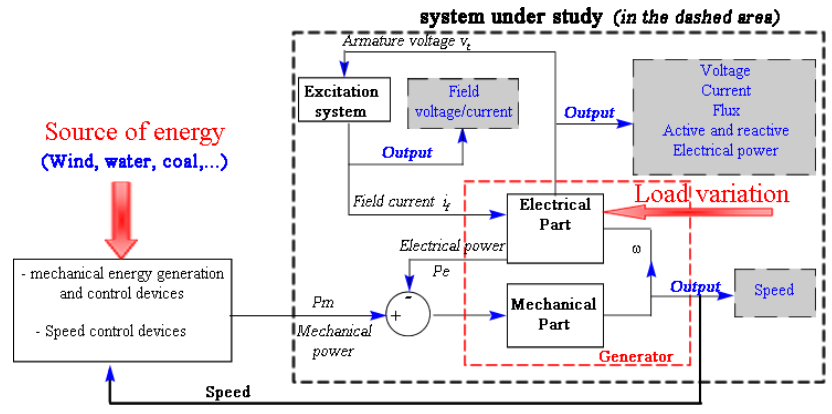

Fig. 1. Presentation of the system

\section{THE MODELING PROCESS OF VARIOUS SUB-SYSTEMS}

This article is mainly focused on the SG model for the purposes of training and education. Therefore, this section describes the process of developing the model according to the desired objectives. The development of equations and the presentation of the results has been the object of a scientific article.

\subsection{The generator}

Among training purposes, the model should be used to perform all simulations and to present the desired curves. Beyond the needs of prediction, it should be used by learners for parameters identification and diagnostics processes. Also, it must facilitate its insertion in power plants that use a SG. To achieve these objectives the modeling process of the generator consisted of modeling various parts and bound together as shown on Fig. Fig. 1.

\subsection{The electric part}

The classical well-known equivalent circuits of SG are given in Fig. 2 below.

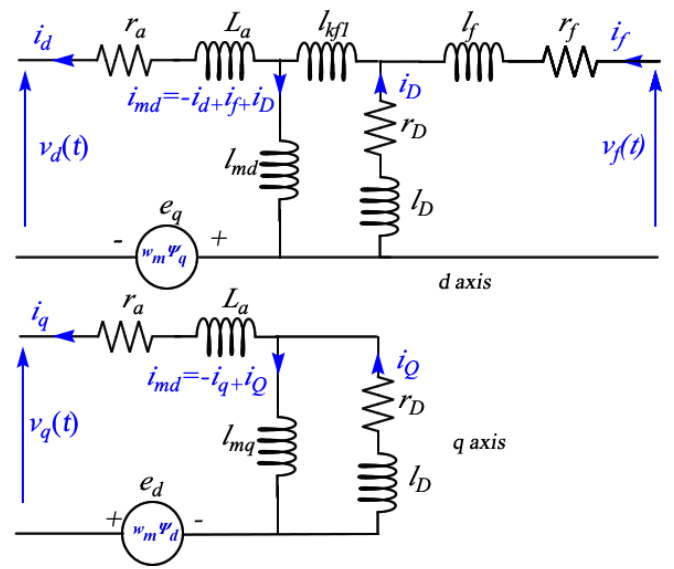

Fig. 2. d-q axis Equivalent circuits of a synchronous generator

The voltages equations of SG can be organized into matrix form as presented in [20].

A major asset of this model is the integration of the load in the state matrices [18]. However, the process of integration and computation of load impedance values is improved. In fact, the model of a local load for an islanded system given by equation (1) is depicted by Fig.3 [21]. The impedance computing process includes the actual values of active and reactive power output. With this impedance value and considering the impedance of 
the line zero, the voltage equation of the load is brought in Park's reference and concatenated [22]. As the load is directly connected to the generator, the equality between the SG armature and the load voltages in Park's reference provides the state model of the electrical part of the SG of (2) $[22]$.

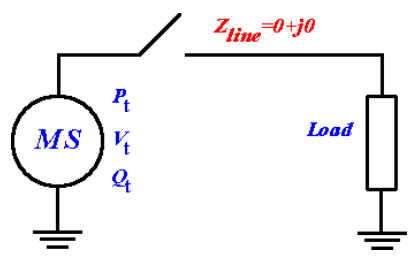

Fig. 3. Generator connected to and islanded load

The load equivalent parameters can be formulated as follows:

$$
r_{l}=\frac{P_{t}}{i_{t}^{2}}=P_{t}\left(\frac{z_{l}}{V_{t}}\right)^{2} \text { and } x_{l}=\frac{Q_{t}}{i_{t}^{2}}=Q_{t}\left(\frac{z_{l}}{V_{t}}\right)^{2}
$$

Where $z_{l}=r_{l}+j x_{l}$ is the per unit load equivalent impedance, $P_{t}, Q_{t}, v_{t}, i_{t}$ are respectively the per unit active and reactive power, terminal voltage and current.

$$
\left\{\begin{array}{l}
p(I)=A_{c} I+B_{c} v_{f} \\
Y=C_{c} I+D_{c} v_{f}
\end{array}\right.
$$

State variables are field currents, observed variables are all currents and voltages, and the control variable is the field voltage. The procedure of getting $A_{C}, B_{C}, C_{C}, D_{C}$ are given in [22].

The ease of the use of exogenous variables in MATLAB/Simulink facilitates the integration of the saturation by re-evaluating the magnetizing reactance, using the saturation factor [17].

\subsection{The mechanical part}

For an isolated load, the dynamic process of the generator unit considering the load characteristic is given in [11]. The model facilitates the use of the speed controller.

\subsection{The excitation system}

The brushless excitation system [23] used in this paper and depicted by Fig. 4 consists of an amplifier, an excitatory, a compensator and a regulator. The procedure of getting its state model (3) is described in detail in [22]. State models offer for the learners, an easy stability study, poles placement, and other related advantages.

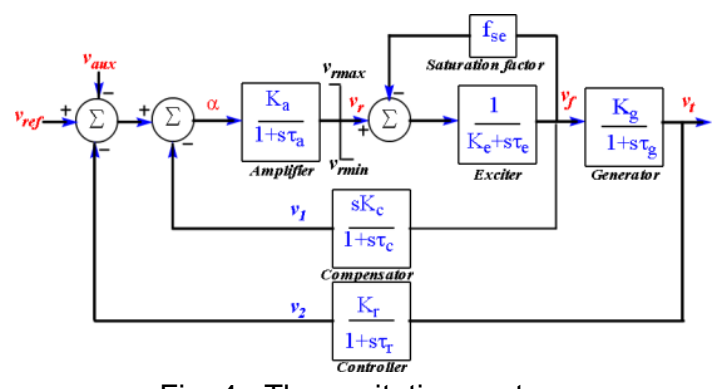

Fig. 4. The excitation system

$$
\left\{\begin{array}{l}
p(e)=A_{e} e+B_{e} v_{r e f} \\
v_{f}=C_{e} e+D_{e} v_{r e f}
\end{array}\right.
$$

Where

$$
e=\left[\begin{array}{lllll}
v_{r} & v_{f} & v_{t} & v_{x} & v_{2}
\end{array}\right]^{t}
$$

Where the state variables are the amplifier output voltage $v_{r}$, the field voltage $v_{f}$, the armature voltage $v_{t}$, the regulator output voltage $v_{2}$ and a transition variable $v_{x}$. The control variable is the reference voltage $v_{\text {ref }}$. Other matrices are set to have the field voltage as observed variable. $A_{e} ; B_{e} ; C_{e} ; D_{e}$ are given in [22].

\subsection{Binding of various part}

The process assembling different blocks is of paramount importance. It facilitates the implementation of the model in most plants using synchronous generators and dynamic simulations. The facilities offered by Simulink through exogenous variables and programs in Sfunctions ease the implementation of model given in Fig. 5. The model of the electrical part is nonlinear due to the change of $\mathrm{d}$ and $\mathrm{q}$ reactance while taking not only the saturation phenomenon into account, but also through the variation of the rotational speed due to the changes in load. The Fig. 5 presents the model as implemented in Matlab/Simulink.

The values of impedances entered into the block of dynamic variation of the load are computed according to (1), based on both the active and reactive output power values. The changes in power are due to the corresponding test scenario. Various tests simulations can be carried out with the proposed model, including field short-circuit test. 


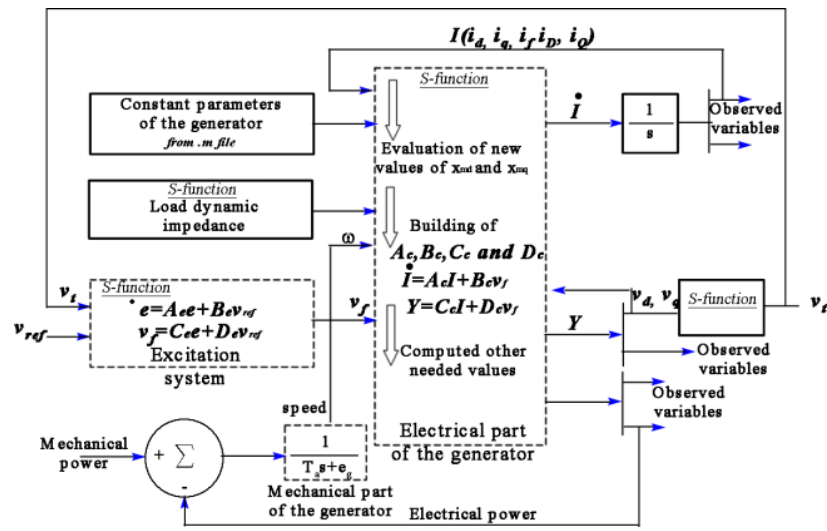

Fig. 5. The implementation structure of the SG in MATLAB/Simulink

\section{Utilization}

The pedagogical advantages of the model presented in this paper reside in the fact that, it can be used to carry out almost all simulations such as: load switching, load rejection, three phase short circuit, field short circuit. As in, real life situation, a series of successive simulations can be performed without the need of initial conditions reevaluation and presents all desired curves. It allows parameter identification, optimization and diagnosis processes.

The process of simulation is performed as follow: The selection of the series of simulation, the computation of impedance values, the inserting of data into the dynamic model of impedance and finally the simulation. As its initial conditions are easy to compute, the simulations start at no load. Table 1 shows the impedance data for the simulations.

Table 1: Impedance values for simulation

\begin{tabular}{|l|l|l|l|}
\hline Simulation & \multicolumn{3}{|l|}{ Impedance values in p.u } \\
\hline & $\boldsymbol{x}_{\boldsymbol{l}}$ & $\boldsymbol{r}_{\boldsymbol{l}}$ & observation \\
\hline No load & 1000 & 1000 & High values \\
\hline With load & $\begin{array}{l}\text { Computed } \\
\text { as in (1) }\end{array}$ & $\begin{array}{l}\text { Computed } \\
\text { as in (1) }\end{array}$ & $\begin{array}{l}\text { For Load } \\
\text { rejection, or load } \\
\text { switching }\end{array}$ \\
\hline $\begin{array}{l}\text { Short } \\
\text { circuit }\end{array}$ & 0 & 0 & \\
\hline
\end{tabular}

\section{RESULTS}

Operations representing real situations used to test the electrical part of the synchronous machine are shown in Fig. 6. The simulation data of the synchronous generator and the load are available in the table 2. It is a generator of 4-poles, $1.5-\mathrm{kVA}, 60-\mathrm{Hz}$, and $208-\mathrm{V}$.

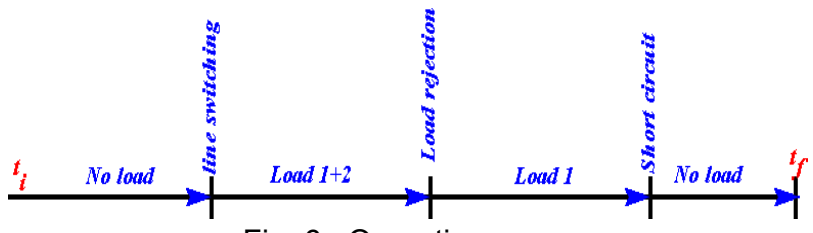

Fig. 6. Operations

Table 2: Data of the synchronous generator and load

\begin{tabular}{|c|c|c|c|}
\hline \multicolumn{4}{|c|}{ Synchronous generator parameters (pu) } \\
\hline $\begin{array}{c}r_{a}= \\
0.0203\end{array}$ & $r_{f}=0.0116$ & $\begin{array}{c}r_{D I}= \\
0.0120\end{array}$ & $x_{m q}=0.3707$ \\
\hline$r_{Q}=0.0073$ & $\begin{array}{c}x_{a}= \\
0.0101\end{array}$ & $x_{f}=0.0713$ & $x_{k f 1}=-0.0081$ \\
\hline$x_{D}=0.669$ & $\begin{array}{c}x_{Q 1}= \\
0.1352\end{array}$ & $x_{m d}=0.6541$ & \\
\hline \multicolumn{4}{|c|}{ Saturation coefficients } \\
\hline \multicolumn{4}{|c|}{$\begin{array}{c}a_{1}=-0.0036 \quad a_{2}=-0.0114 \quad a_{3}=0.0573 \quad a_{4}=-0.0645 \\
a_{5}=0.0282 \quad a_{6}=-0.0057 \quad a_{7}=0.0004\end{array}$} \\
\hline \multicolumn{4}{|c|}{ Initial conditions (pu) } \\
\hline $\begin{array}{c}i_{d 0}= \\
0.39986\end{array}$ & $\begin{array}{c}i_{q 0}= \\
0.54634\end{array}$ & $\begin{array}{c}i_{f 0}= \\
0.84061\end{array}$ & $\begin{array}{c}v_{f 0}= \\
9.7511 \mathrm{e}-3\end{array}$ \\
\hline$i_{D}=0$ & $i_{Q}=0$ & & \\
\hline \multicolumn{4}{|c|}{ Load values } \\
\hline \multicolumn{2}{|c|}{ State } & rc (pu) & $\mathrm{xc}(\mathrm{pu})$ \\
\hline No & oad & 1000 & 1000 \\
\hline \multicolumn{2}{|c|}{ Load $1+2$} & 0.324 & 0.325 \\
\hline \multicolumn{2}{|c|}{ Load 1} & 0.1 & 0.1 \\
\hline \multicolumn{2}{|c|}{ Short circuit } & 0 & 0 \\
\hline
\end{tabular}

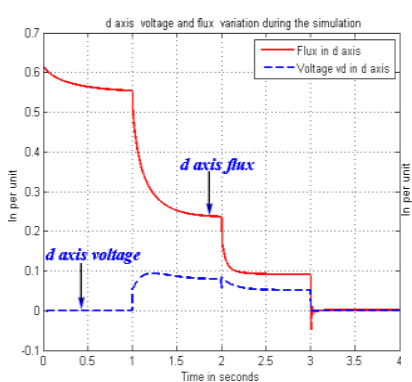

a)

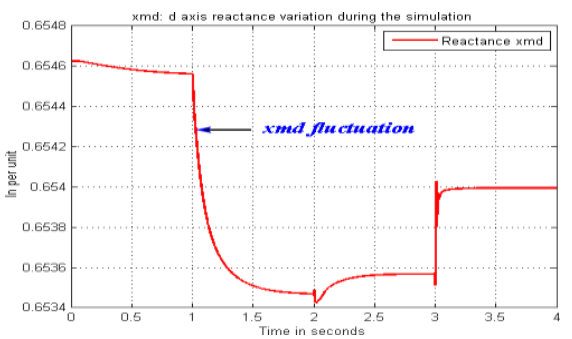

c)

Fig. 7. Some results of electrical part: a) $d$ axis voltage and flux; b) d axis and field currents; c) xmd fluctuation 
These results present the versatile, dynamic, flexible and non linear aspects of the SG. The series of successive operations starts from a single initial condition. The variation of the $d$ and $q$ axis reactances is presented by Fig. 7-c. They are adapted in real time in the state matrix of the equation (2). The instability of the curves after transient states is due to the absence of the excitation system and it AVR. The rotation speed is considered constant at $1 \mathrm{pu}$. These two situations are corrected while implementing the model in a hydroelectric plant of the Fig. 8. This structure strictly complies with all the explanations in the first part of this document. Primary energy here is provided by the hydroelectric dam. The sequence of operations performed as common in plants is shown on Fig. 6. The related values of equivalent impedances and of various parts used for simulation are available in [22]. It is the full model of the SG of 231.6 MW inserted in a hydroelectric power plant.

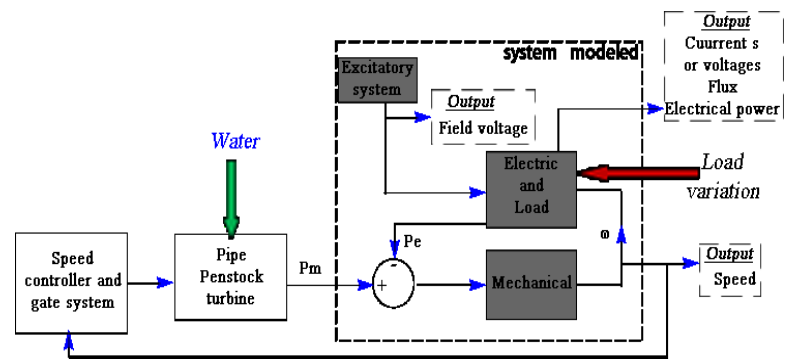

Fig. 8. Generator integrated in a hydro plant



a)

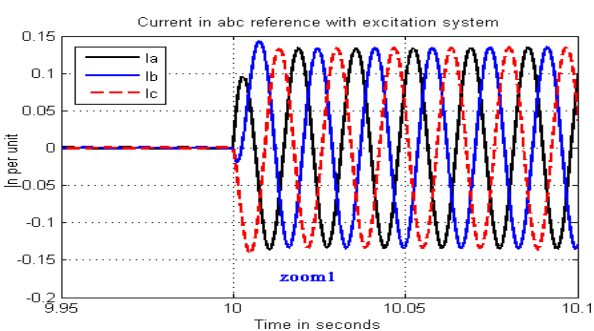

b)

Fig. 9. Results of the armature currents in abc reference when inserting the generator in and electrical generation system: a) All the simulation; b) Zoom at load switching
These results illustrate the dynamic and versatile features of the SG model presented in this paper. Given the possibility of successive and progressive simulation, it is not necessary to repeatedly evaluate initial conditions. The simulation can therefore start at no load where the initial conditions are easy to compute and then evolve towards the desired state. The excitation system and its AVR are essential for maintaining the armature voltage constant after the transient states. However the overall system is kept in balance by a combined action between the excitation system and the speed controller. All desired curves can be observed. The model is suitable for electrical power generation systems using a SG.

\section{CONCLUSION}

This article presents a dynamic nonlinear model of the SG made of both an electrical and a mechanical part, and the excitation system with it regulator (AVR). The model that easily integrates the saturation, allows a succession of operation as in real life situation, without the need for initial conditions re-evaluation. The state model of the electrical part and the strengths of Matlab / Simulink software are combined for presenting all the desired curves. It is a suitable model for the determination of the parameters and other specific techniques used with state models. It fits easily into the system of production of electrical energy using synchronous generators such as hydroelectric plant presented in the last section. It is therefore, a versatile and flexible model, suitable for student in numerical laboratory works with a SG.

\section{References}

[1] D. Santos-Martin, J. Alonso-Martinez, J. Eloy-Garcia Carrasco, and S. Arnaltes, "Problem-based learning in wind energy using virtual and real setups," Education, IEEE Transactions on, vol. 55, pp. 126-134, 2012.

[2] F. Martinez, L. C. Herrero, and S. De Pablo, "Project-based learning and rubrics in the teaching of power supplies and photovoltaic electricity," Education, IEEE Transactions on, vol. 54, pp. 87-96, 2011.

[3] A. J. Saavedra Montes, H. A. B. Castro, and J. H. Riveros, "How to motivate students to work in the laboratory: A new approach for an electrical machines laboratory," Education, IEEE Transactions on, vol. 53, pp. 490-496, 2010.

[4] S. Li and A. A. Khan, "Applying it tools to a laboratory course for measurement, analysis, and design of electric and electronic circuits," Education, IEEE Transactions on, vol. 48, pp. 520-530, 2005.

[5] S. Shirsavar, B. A. Potter, and I. M. Ridge, "Three-phase machines and drives-equipment for a laboratory-based course," Education, IEEE Transactions on, vol. 49, pp. 383 $388,2006$. 
[6] A. Bentounsi, H. Djeghloud, H. Benalla, T. Birem, and H. Amiar, "Computer-aided teaching using MATLAB/Simulink for enhancing an IM course with laboratory tests," Education, IEEE Transactions on, vol. 54, pp. 479-491, 2011.

[7] M. D. Koretsky, D. Amatore, C. Barnes, and S. Kimura, "Enhancement of student learning in experimental design using a virtual laboratory," Education, IEEE Transactions on, vol. 51, pp. 76-85, 2008.

[8] M. H. Knudsen, "Experimental modeling of dynamic systems: an educational approach," Education, IEEE Transactions on, vol. 49, pp. 29-38, 2006.

[9] G. C. Goodwin, A. M. Medioli, W. Sher, L. Vlacic, and J. S. Welsh, "Emulation-based virtual laboratories: a low-cost alternative to physical experiments in control engineering education," Education, IEEE Transactions on, vol. 54, pp. 48-55, 2011.

[10] J. Machowski, J. Bialek, S. Robak, and J. Bumby, "Excitation control system for use with synchronous generators," in Generation, Transmission and Distribution, IEE Proceedings-, 1998, pp. 537-546.

[11] H. Fang, L. Chen, N. Dlakavu, and Z. Shen, "Basic modeling and simulation tool for analysis of hydraulic transients in hydroelectric power plants," Energy Conversion, IEEE Transactions on, vol. 23, pp. 834-841, 2008.

[12] W. G. o. P. M. a. E. Supply, "Models for System Dynamic Performance Studies, Hydraulic Turbine and Turbine Control Models For System Dynamic Studies," IEEE Transactions on Power Systems, vol. vol. 7, No. 1, , pp. 167-179, February 1992.

[13] J. Codrington, M. Harrison, L. Pereira, and H. Falvey, "Computer Representation of Electrical System Interaction with a Hydraulic Turbine and Penstock," Power Apparatus and Systems, IEEE Transactions on, pp. 26112618, 1982.

[14] A. Demiroren and H. Zeynelgil, "Modelling and simulation of synchronous machine transient analysis using Simulink," International Journal of Electrical Engineering Education, vol. 39, pp. 337-346, 2002.

[15] A. Ben-Abdennour and K. Y. Lee, "A decentralized controller design for a power plant using robust local controllers and functional mapping," Energy Conversion, IEEE Transactions on, vol. 11, pp. 394-400, 1996.

[16] M. S. Matti and D. A. Al-Nimma, "Reactive Power Control of an Alternator with Static Excitation System Connected to a Network." Al-Rafidain Engineering, Vol.18, No.3 PP. 29-45, June 2010

[17] R.Wamkeue, F.Baetscher, and I.Kamwa, "Hybrid State Model Based Time-Domain Identification of Synchronous Machine Parameters from Saturated Load Rejection Test Records," IEEE Trans. on Eng Conv, vol. 23, no 1, pp. pp 68-77, Mar 2008(IEEE PES 2009's best paper award).

[18] E. B. Mouni, "Contribution à l'amélioration des performances des génératrices synchrones: nouvelle structure d'excitation basée sur une machine à aimants et combinée à des lois de commande avancées," These de Doctorat, université de Poitiers, Ecole Nationale Supérieure d'Ingénieurs de Poitiers, 2008.
[19] J. W. Tsotie and R. Wamkeue, "Development of an analog and didactical simulator for hydroelectric power plants," Proceedings of the Canadian Engineering Education Association, 2013.

[20] R. Wamkeue, I. Kamwa, and X. Dai-Do, "Short-circuit test based maximum likelihood estimation of stability model of large generators," Energy Conversion, IEEE Transactions on, vol. 14, pp. 167-174, 1999.

[21] R.Wamkeue, C.Jolette, and I.Kamwa, "Advanced model for analysis and on-line assessment of a synchronous generator under line-switching and load-rejection tests," IEEE Trans. Eng Conv, vol. 25 No 3, 2010.

[22] J. W. Tsotie, "Modélisation et implémentation numérique du simulateur analogique de la centrale Hydro-Québec," Maîtrise en ingenierie, École d'ingenierie, UQAT, Décembre, 2013.

[23] P. M. Anderson and A. A. Fouad, Power system control and stability: John Wiley \& Sons, 2008. 